Research Paper

\title{
NLS-RAR $\alpha$ Promotes Proliferation and Inhibits Differentiation in HL-60 Cells
}

\author{
Xiu-Xiu Hu ${ }^{1,2}$, Liang Zhong'2, Xi Zhang 2, Yuan-Mei Gao ${ }^{2}$, Bei-Zhong Liu ${ }^{1,2}{ }^{\bowtie}$ \\ 1. Central Laboratory of Yong-chuan hospital, Chongqing Medical University, Chongqing 402160, China. \\ 2. Key Laboratory of Laboratory Medical Diagnostics, Ministry of Education, Department of Laboratory Medicine, Chongqing Medical \\ University, Chongqing 400016, China.
}

$\triangle$ Corresponding author: Bei-Zhong Liu, Department of Laboratory Medicine, Chongqing Medical University, 1\#, Yixueyuan Road, Chongqing, 400016, China. Tel:+86 18716474304, Fax: +86 023-68485006; E-mail: liubeizhong@cqmu.edu.cn.

() Ivyspring International Publisher. This is an open-access article distributed under the terms of the Creative Commons License (http://creativecommons.org/ licenses/by-nc-nd/3.0/). Reproduction is permitted for personal, noncommercial use, provided that the article is in whole, unmodified, and properly cited.

Received: 2013.04.20; Accepted: 20I3.12.24; Published: 20I4.0I.16

\begin{abstract}
A unique mRNA produced in leukemic cells from a $t(15 ; 17)$ acute promyelocytic leukemia (APL) patient encodes a fusion protein between the retinoic acid receptor $\alpha$ (RAR $\alpha)$ and a myeloid gene product called PML. Studies have reported that neutrophil elastase (NE) cleaves bcr-I-derived PML-RAR in early myeloid cells, leaving only the nuclear localization signal (NLS) of PML attached to RARa. The resultant NLS-RARa fusion protein mainly localizes to, and functions within, the cell nucleus. It is speculated that NLS-RAR $\alpha$ may act in different ways from the wild-type RAR $\alpha$, but its biological characteristics have not been reported. This study takes two approaches. Firstly, the NLS-RAR $\alpha$ was silenced with pNLS-RARa-shRNA. The mRNA and protein expression of NLS-RAR $\alpha$ were detected by RT-PCR and Western blot respectively. Cell proliferation in vitro was assessed by MTT assay. Flow cytometry (FCM) was used to detect the differentiation of cells. Secondly, the NLS-RAR $\alpha$ was over-expressed by preparation of recombinant adenovirus HL-60/pAd-NLS-RARa. The assays of mRNA and protein expression of NLS-RARa, and cell proliferation, were as above. By contrast, cell differentiation was stimulated by all trans retinoic acid (ATRA) $(2.5 \mu \mathrm{mol} / \mathrm{L})$ at $24 \mathrm{~h}$ after virus infection of pAd-NLS-RARa, and then detected by CDI Ib labeling two days later. The transcription and translation of C-MYC was detected in HL-60/pAd-NLS-RARa cells which treated by ATRA. Our results showed that compared to the control groups, the expression of NLS-RARa was significantly reduced in the HL-60/pNLS-RARa-shRNA cells, and increased dramatically in the HL-60/pAd-NLS-RAR $\alpha$ cells. The proliferation was remarkably inhibited in the HL-60/pNLS-RARa-shRNA cells in a time-dependent manner, but markedly promoted in the HL-60/pAd-NLS-RAR $\alpha$ cells. FCM outcome revealed the differentiation increased in HL-60/pNLS-RARa-shRNA cells, and decreased in the HL-60/pAd-NLS-RAR $\alpha$ cells treated with $2.5 \mu \mathrm{mol} / \mathrm{L}$ ATRA. The expression of C-MYC increased strikingly in HL-60/pAd-NLS-RAR $\alpha$ cells treated with $2.5 \mu \mathrm{mol} / \mathrm{L}$ ATRA. Down-regulation of NLS-RAR $\alpha$ expression inhibited the proliferation and induced the differentiation of HL-60 cells. On the contrary, over-expression of NLS-RARa promoted proliferation and reduced the ATRA-induced differentiation of HL-60 cells.
\end{abstract}

Key words: NLS-RARa, shRNA, over-expression, HL-60 cell, proliferation, differentiation

\section{Introduction}

The retinoic acid receptor-alpha (RARA) gene is located on chromosome 17q21, in proximity to the breakpoint of APL[1], and is thought to play a critical role in the pathogenesis of APL. The product of the RARA gene, the RARa protein, is a member of the nuclear steroid/thyroid hormone receptor superfam- 
ily $[2,3,4]$. It modulates the expression of target genes by acting as a ligand-dependent transcription factor, which is stimulated by ATRA $[5,6,7]$. The amino acid sequence of RARa has been divided into six regions (A-F) based on different degrees of conservation, with regions $\mathrm{C}$ and $\mathrm{E}$ being highly conserved, binding to target DNA and the ligand separately [8]. Promyelocytic leukemia (PML) which contains nuclear localization signal (NLS), B-Boxes and a-helical coiled-coil region, is encoded by PML gene mapped on chromosome 15q22 in humans. [9] In 1991, it was discovered that the consistent chromosomal translocation of APL, $t(15: 17)$, fused the retinoic acid receptor a (RA$\mathrm{Ra})$ gene to the promyelocytic leukemia (PML) gene on chromosome 15[10], yielding the fusion protein PML-RARa [11], which represents the etiologic agent of APL. This translocation is detected in as many as $90 \%$ of APL patients and has become the definitive marker for the disease [12]. The aberrant PML-RARa fusion product plays a vital role in APL [13]. Some studies have demonstrated that the transgenic and knock-in animals expressing PML-RARa in early myeloid cells [14, 15, 16] developed acute promyelocytic leukemia (APL), but APL was absent when PML-RARa was expressed in late myeloid cells [17]. However, the mechanisms by which PML-RARa predisposes early myeloid cells to eventual leukemic transformation are not yet completely clear. Recently, some studies declared that neutrophil elastase (NE), an early myeloid-specific serine protease, is important for the development of APL in mice. Furthermore, NE
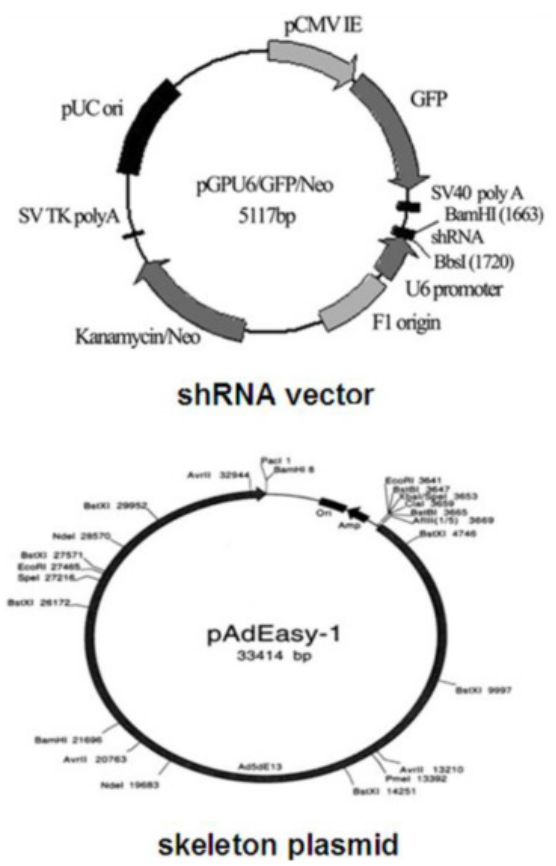

can cleave bcr-1 derived PML-RARa protein in early myeloid cells [18], resulting in removal of NLS from PML, and attaching to RARa]. The resultant fusion of RARa with NLS was named NLS-RARa. The NLS-RARa gene is about 1506 bp in length and encodes a protein of $61 \mathrm{kD}$. These data suggested that the disruption of RARa protein may be the major cause of APL. So far, few studies have focused on the biological functions of NLS-RARa which probably has remarkable value for the genesis and development of APL. At present, gene therapy is developing rapidly, and every gene which plays a significant role and has significant values in APL can be therapeutic target gene. So, we contribute ourselves to study the gene function of NLS-RARa gene, in order to conform that it has potential therapeutic value. This work is mainly aimed to the biological function of NLS-RARa gene.

In order to explore the biological characteristics of NLS-RARa gene, the NLS-RARa was alternately silenced with shRNA, or over-expressed by from an adenovirus vector. Differentiation of the acute premyeloid leukemia (APL) cell line HL-60 can be induced by all trans-retinoic acid (ATRA) [19]. Thus, HL-60 cells were infected with adenovirus vector and treated with $2.5 \mu \mathrm{mol} / \mathrm{L}$ ATRA, then examined for cell differentiation.

\section{Materials and methods}

\section{Vector maps}

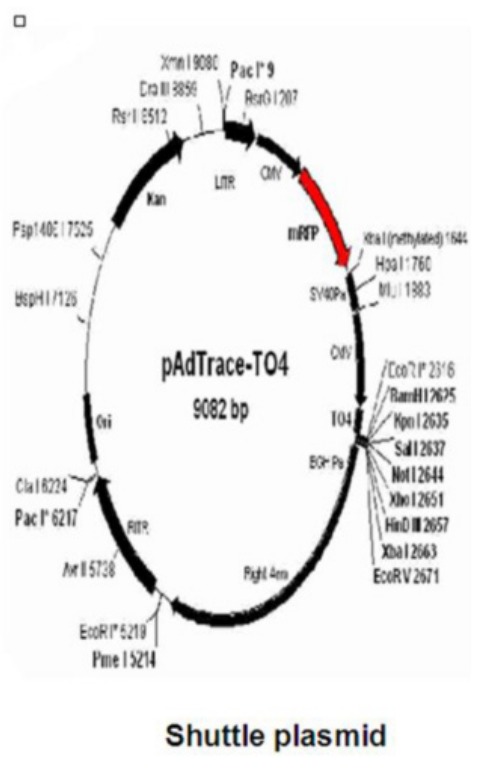

Figure A. Vector maps 


\section{Cell line and culture}

Human HL-60 cells were purchased from the Shanghai Institute for Biological Science and maintained in IMDM (Gibco, MD, USA) supplemented with $20 \%$ fetal bovine serum (FBS; Gibco, MD, USA) in an environment with $5 \% \mathrm{CO}_{2}$ at $37^{\circ} \mathrm{C}$.

Human K562 cells were saved by our own laboratory and maintained in IMDM (Gibco, MD, USA) supplemented with $10 \%$ fetal bovine serum (FBS; Gibco, MD, USA) in an environment with $5 \% \mathrm{CO}_{2}$ at $37^{\circ} \mathrm{C}$.

AD293 cells were saved by our own laboratory and cultured in DMEM (Gibco, MD, USA) containing $10 \%$ fetal bovine serum (FBS; Gibco, MD, USA) in an environment with $5 \% \mathrm{CO}_{2}$ at $37^{\circ} \mathrm{C}$.

\section{Transient Transfection}

HL-60 cells $\left(2.5 \times 10^{5} / \mathrm{ml}\right)$ in logarithmic growth phase were seeded in 6-well plate. For transfection, $2.5 \mu \mathrm{g}$ of plasmid pPML(NLS-)-shRNA was diluted in $500 \mu \mathrm{l}$ Opti-MEM I, which was added to each well. Then, $2.5 \mu l$ of PLUS ${ }^{\text {TM }}$ Reagent was directly added to dilute DNA. After gentle mixing and incubation for 15 min at room temperature, $13.75 \mu$ of Lipofectamine ${ }^{\mathrm{TM}}$ LTX was added into above DNA solution, followed by incubation for $25 \mathrm{~min}$ at room temperature. The resultant solution was added to each well. After incubation at $37^{\circ} \mathrm{C}$ for $6 \mathrm{~h}, 1 \mathrm{ml}$ of fresh complete medium was added. These transfected cells were named as HL-60/pNLS-RARa-shRNA. In the negative control group, HL-60/pshRNA-NC cells were processed similarly. At $48 \mathrm{~h}$ after transfection, the successfully transfected cells were verified by fluorescent microscopy. The transfection efficiency was expressed as the percentage of GFP-positive cells. There were three groups in this experiment: HL-60 cells group, HL-60/pshRNA-NC group and HL-60/pNLSRARa-shRNA group.

\section{Cell infection by adenovirus}

HL-60 cells in logarithmic growth phase $\left(5 \times 10^{5} /\right.$ well $)$ were seeded in 6 -well plate. These cells were infected with adenovirus vectors, $\mathrm{pAd}-\mathrm{KZ}$ or the NLS-RARa-expressing recombinant adenovirus, pAd-NLS-RARa, and both of them express RFP (Red Fluorescent Protein). Meanwhile, polybrene was also added, as per manufacturer's instructions. After culture for $8-12 \mathrm{~h}$, the medium was refreshed. The fluorescence was then detected $48 \mathrm{~h}$ later. There were three groups in this experiment: HL-60 cells group, HL-60/pAd-KZ groups, and HL-60/pAd-NLS-RARa group.

\section{RNA isolation and RT-PCR}

Total RNA was extracted from cells in each group using Trizol reagent, as per manufacturer's instructions (Invitrogen, Carlsbad, California). The first-strand cDNA was synthesized from $1 \mu \mathrm{g}$ of total RNA using a Prime Script Kit (TAKARA, Dalian, China). NLS-RARa gene expression was quantified by reverse transcriptase polymerase chain reaction (RT-PCR) with cDNA Synthesis Kit (TAKARA, Dalian, China). $\beta$-actin was used as an endogenous control. All samples were run in duplicate for each experiment. Do $1 \%$ agarose gel lelctrophoresis as soon as we acquire the PCR product. And $5 \mu \mathrm{l}$ PCR product was used in each lane. Gene expression analysis was performed with the Quantity One Software (BIO-RAD, USA). The PCR conditions were: pre-denaturation at $95^{\circ} \mathrm{C}$ for $5 \mathrm{~min}, 35$ cycles of denaturation at $95^{\circ} \mathrm{C}$ for $30 \mathrm{~s}$, annealing at $64^{\circ} \mathrm{C}$ for $30 \mathrm{~s}$, and extension at $72{ }^{\circ} \mathrm{C}$ for $100 \mathrm{~s}$, and a final extension at $72{ }^{\circ} \mathrm{C}$ for $5 \mathrm{~min}$. The amplification of $\beta$-actin gene was the as for NLS-RARa. The mRNA expression levels of the target gene were normalized to those of $\beta$-actin. The specific primers for NLS-RARa were 5'ATGTACGCCTTCTCCATCAAA -3' (forward) and 5'TCACGGGGAGTGGGTG -3' (reverse). Those for $\beta$-actin were 5'-CACCACACCTTCTACAATGAGC-3' (forward) and 5'-GTGATCTCCTTCTGCATCCTGT-3' (reverse).

\section{Western blot analysis}

Cells in each group were washed with ice-cold phosphate-buffered saline and lysed in RIPA solution containing protease inhibitor cocktail. Protein concentration was determined with BCA method. A total of $100 \mu \mathrm{g}$ of protein was added in $12 \%$ sodium dodecyl sulfate-polyacrylamide gel, and then transferred to polyvinylidene difluoride membrane. The membrane was blocked with 5\% non-fat milk for $4 \mathrm{~h}$, then incubated with primary antibody overnight at $4{ }^{\circ} \mathrm{C}$ (rabbit polyclonal antibody against RARa; 1:1000; Santa Cruz, SC-551, USA) and then with secondary antibody (goat anti-rabbit antibody, 1:1000, Zhongshan Goldenbridge Biotechnology Co. Ltd., Beijing, China [ conjugate]) for $1 \mathrm{~h}$ at $37^{\circ} \mathrm{C}$. After washing with Tris-Buffered Saline Tween-20 (TBST), the autoradiograms were scanned and subjected to densitometry. $\beta$-actin (mouse monoclonal antibody against $\beta$-actin, 1:500; Zhongshan Goldenbridge Biotechnology Co., Ltd., Beijing, China) was used as an internal control. Protein bands were visualized using the Quantity One Software (BIO-RAD, USA).

\section{MTT proliferation assay}

To assess cell viability, cells in each group were seeded in 96-well plates at a density of $1.0 \times 10^{4}$ cells/well. Cell proliferation was quantified at 4 days post-treatment by MTT assay. In brief, $20 \mu \mathrm{l}$ of MTT (5 
$\mathrm{mg} / \mathrm{ml}$; Sigma, MO, USA) was added to each well followed by incubation for $4 \mathrm{~h}$ at $37^{\circ} \mathrm{C}$. The medium was then replaced with $150 \mu$ of dimethylsulphoxide (DMSO, Sigma, MO, USA). The cell viability was assessed by detection of absorbance at $492 \mathrm{~nm}$ using a spectrophotometer. Cells growth curves were plotted. The experiment was repeated at least three times.

\section{Flow cytometry}

For detection of the cell differentiation antigen CD11b, $1 \times 10^{6}$ cells in each group were washed twice with PBS, incubated with PE-conjugated CD11b antibody or PE-conjugated IgG1isotype control antibody at $4^{\circ} \mathrm{C}$ for $30 \mathrm{~min}$ and analyzed by flow cytometry using a FACScan flow cytometer and Cell Quest software (Becton Dickinson, Mountain View, CA). The expression rate of CD11b positive cells was determined from $1 \times 10^{4}$ cells for each group.

To preferably evaluate the differentiation level of infection group, besides the treatment of polybrene and a variety of adenoviruses, $2.5 \mu \mathrm{mol} / \mathrm{L}$ ATRA was added into each well in each group to induce the differentiation of HL-60 cell of each group. After incubation for $48 \mathrm{~h}$, cells of each group were processed as described above.

\section{Detection of expression of differentiation-related genes by RT-PCR and Western blot assay}

The extraction of total RNA and reverse transcription into cDNA were the same as described above. The specific primers for the fusion gene were 5'-CCTACCCTCTCAACGACAGC-3' (forward) and 5'-CTCTGACCTTTTGCAAGGAG-3' (reverse). Those for $\beta$-actin were the same as the above. PCR condition was as follow: pre-denaturation at $95^{\circ} \mathrm{C}$ for $5 \mathrm{~min} ; 35$ cycles of denaturation at $95^{\circ} \mathrm{C}$ for $30 \mathrm{~s}$, annealing at $56^{\circ} \mathrm{C}$ for $30 \mathrm{~s}$ and extension at $72^{\circ} \mathrm{C}$ for $45 \mathrm{~s}$; a final extension at $72^{\circ} \mathrm{C}$ for $5 \mathrm{~min}$. The products were electrophoresed on $1.5 \%$ agarose gel and analyzed with Quantity One Software (BIO-RAD, USA).

Protein concentrations in the cell lysates were determined by BCA protein assay kit (Bi Yun Tian, Shang Hai). Equal amounts of proteins $(50 \mu \mathrm{g})$ were separated by sodium dodecyl sulfate polyacrylamide gel electrophoresis and blotted onto nitrocellulose sheets. The proteins were then probed with the mouse monoclonal antibody C-MYC (Zhongshan Goldenbridge Biotechnology Co., Ltd., Beijing, China) and goat anti-mouse secondary antibodies (Zhongshan Goldenbridge Biotechnology Co., Ltd., Beijing, China). Protein bands were visualized using the Quantity One Software (BIO-RAD, USA).

\section{Statistical analysis}

Data was expressed as mean \pm standard deviation (SD). Statistical analysis was performed with SPSS version 16.0. Independent sample t-test was employed for comparing the means between two groups. A value of $\mathrm{P}<0.05$ was considered statistically significant.

\section{Results}

\section{Fluorescent protein expression in HL-60 cells}

The pNLS-RARa-shRNA was introduced in HL-60 cells to silence NLS-RARa expression. The GFP-positive cells were $84 \%$ at $48 \mathrm{~h}$ after transfection (Figure 1A).

Meanwhile, recombinant adenovirus pAd-NLS-RARa was used to infect HL-60 cells to induce NLS-RARa over-expression. The percentage of RFP-positive cells was about $70 \%$ at $48 \mathrm{~h}$ after infection (Figure 1B).

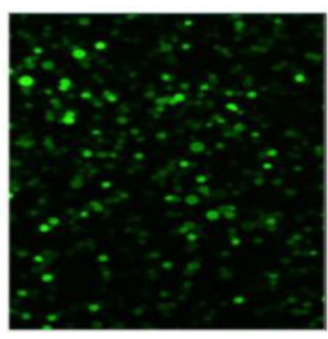

(a)

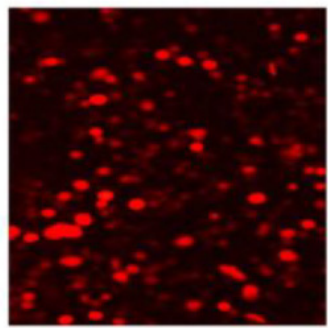

(a)

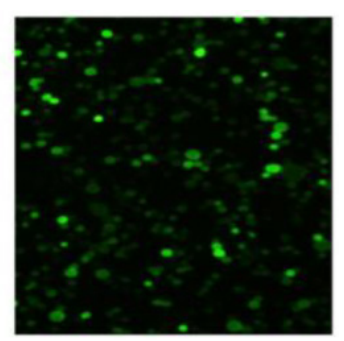

(b)

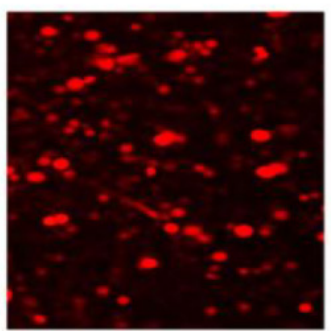

(b)
Figure I. Fluorescent protein expression in HL-60 cells of each group. A, GFP protein expression in transfected cells was detected by fluorescence microscopy $(\times 100)$. (a) HL-60/pshRNA-NC cells; (b) HL-60/pNLS-RARa-shRNA cells. B, RFP protein expression in infected cells was detected by fluorescence microscopy $(\times 100)$. (a) HL-60/pAd-KZ cells; (b) HL-60/pAd-NLS-RARa cells.

\section{Down-regulation of NLS-RAR $\alpha$ in HL-60/pNLS-RAR $\alpha-s h R N A$ cells}

RT-PCR and Western blot assay showed that mRNA and protein expression of NLS-RARa were significantly lowered in the HL-60/pNLS-RARashRNA cells when compared with control group $(\mathrm{P}<0.05$, Figure 2). No significant difference in the 
mRNA and protein expressions of NLS-RARa was found between HL-60 cells and HL-60/pshRNA-NC cells ( $\mathrm{P}>0.05$, Figure 2$)$.

\section{Up-regulation of NLS-RARa in HL-60/pAd-NLS-RAR $\alpha$ cells}

The mRNA and protein
NLS-RARa were also detected in cells with NLS-RARa over-expression by RT-PCR and western blot assay. Results revealed that NLS-RARa expression in the HL-60/pAd-NLS-RARa cells was significantly higher than those in the control groups $(\mathrm{P}<0.05$, Figure 3).

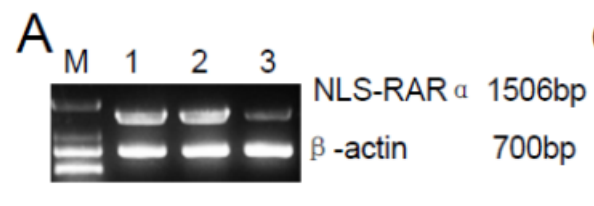

B
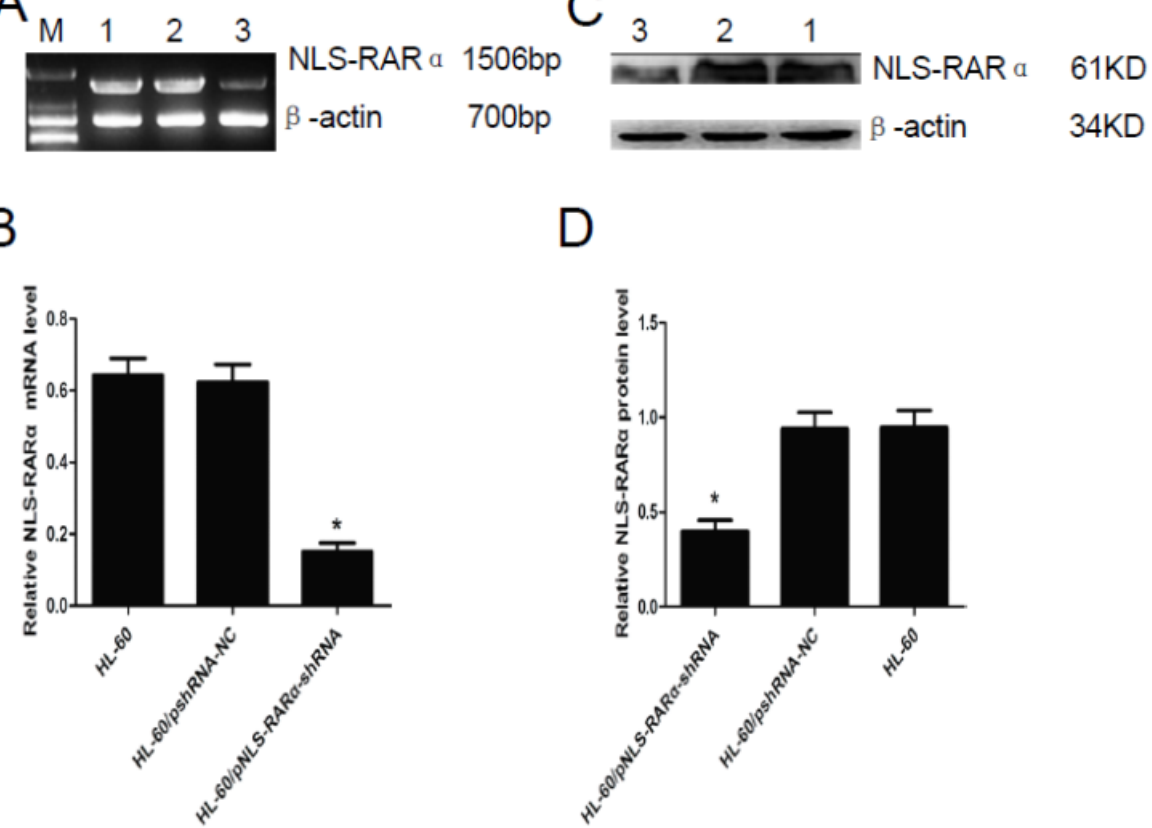

D

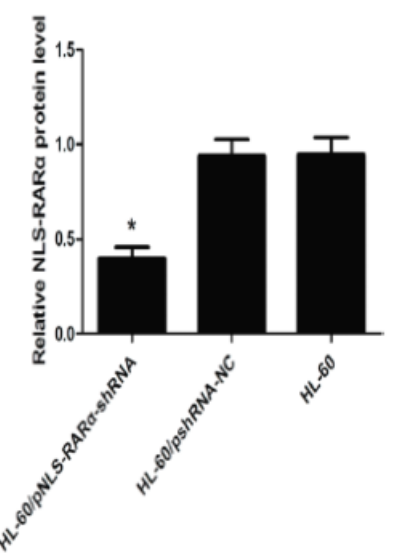

Figure 2. Expression of NLS-RARa in transfected cells. A and B, mRNA expression of NLS-RARa was detected by RT-PCR. The mRNA expression of NLS-RARa in the HL-60/pNLS-RARa-shRNA cells was significantly decreased when compared with control group. Data was expressed as means $\pm S D$. $* P<0.05$. C and D, Protein expression of NLS-RAR $\alpha$ was assessed by Western blot assay. The protein expression of NLS-RAR $\alpha$ in the HL-60/pNLS-RARa-shRNA cells was significantly decreased when compared with the controls. Data was expressed as means \pm SD. * P $<0.05$ (lane I: HL-60 cells; lane 2: HL-60/pshRNA-NC cells; lane 3: HL-60/pNLS-RARa-shRNA cells).

A

M 123

C

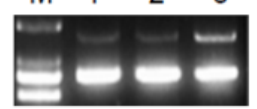

NLS-RAR a 1506 bp

$\begin{array}{lll}3 & 2 & 1\end{array}$

B -actin $\quad 700 \mathrm{bp}$

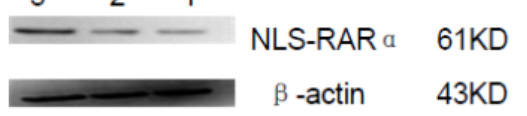

B
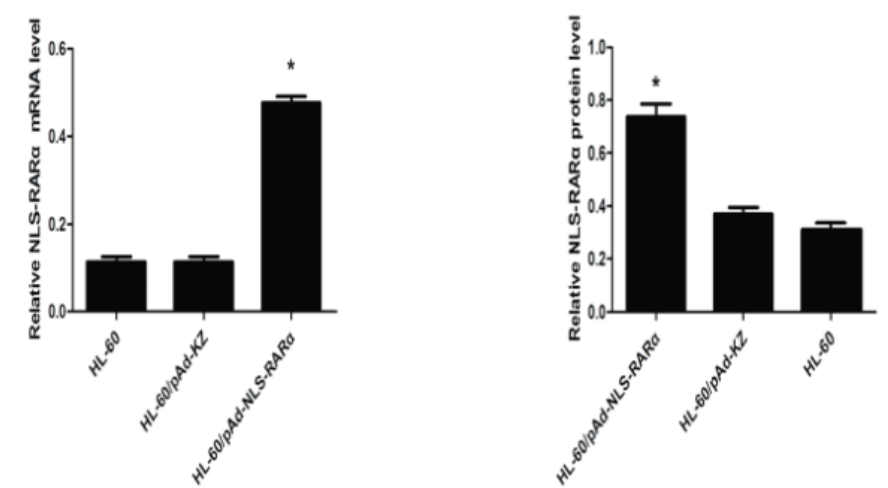

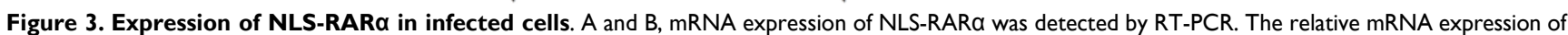
NLS-RAR $\alpha$ in the HL-60/pAd-NLS-RAR $\alpha$ cells was significantly increased when compared with the control group. Data was expressed as means \pm SD. $* P<0.05$. $C$ and $D$, The protein expression of PNLS-RAR $\alpha$ was assessed by Western blot assay. The protein expression of NLS-RARa in the HL-60/pAd-NLS-RAR $\alpha$ cells was significantly higher than control groups. Data was expressed as means \pm SD. ${ }^{*} \mathrm{P}<0.05$ (lane I: HL-60 cells; lane 2: HL-60/pAd-KZ cells; lane 3: HL-60/pAd-NLS-RARa cells). 


\section{Effect of NLS-RARa on proliferation of HL-60 cells}

MTT assay showed that, when compared with the HL-60/pshRNA-NC cells, the proliferation of HL-60/pshRNA-NLS-RARa cells was significantly inhibited in a time-dependent manner $(\mathrm{P}<0.05$, Figure $4 \mathrm{~A})$. In addition, up-regulation of NLS-RARa could promote the proliferation of HL-60 cells (Figure 4B).

\section{Cell differentiation}

As shown in Figure 5, the differentiation rate of HL-60/pNLS-RARa-shRNA group $(2.58 \pm 0.21 \%)$ was significantly higher than that of the control groups $(0.32 \pm 0.03 \%$ and $0.34 \pm 0.06 \%) 48 \mathrm{~h}$ after transfection ( $\mathrm{P}$ $<$ 0.05). The differentiation rate of the
HL-60/pAd-NLS-RARa transfected group $(15.99 \pm 2.08 \%)$ was markedly lower than that of the control groups $(36.37 \pm 3.20 \%$ and $39.33 \pm 3.00 \%)$ after treatment with ATRA for $48 \mathrm{~h}(\mathrm{P}<0.05)$.

\section{Expressions of C-MYC gene in HL-60/ pAd-NLS-RAR $\alpha$ cells}

The expression of C-MYC gene was detected by RT-PCR and Western blot assay. Results showed that, when compared with controls, the mRNA (Figure 6, A and $\mathrm{B}$ ) and protein (Figure 6, C and D) expressions of C-MYC in HL-60/pAd-NLS-RARa cells increased markedly $(\mathrm{P}<0.05)$. These findings suggested that NLS-RARa could inhibit cell differentiation through promoting the expression of C-MYC.
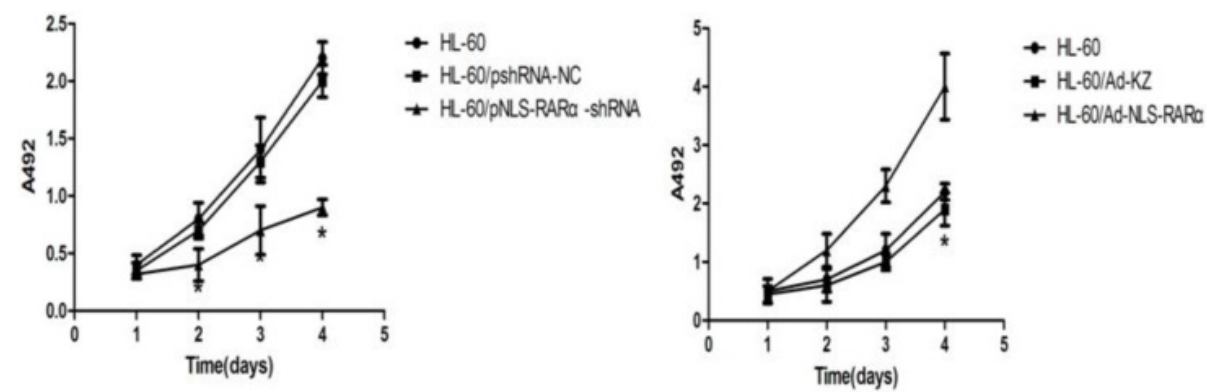

Figure 4. Proliferation of HL-60 cells in different groups. MTT assays were used to measure[/record/assay] cell proliferation on days I, 2, 3 and 4 post-transfection/infection. Absorbance was measured at $492 \mathrm{~nm}$. A, The proliferation of pNLS-RARa-shRNA cells was significantly inhibited in a time-dependent manner. Data was expressed as means $\pm \mathrm{SD}$. $* \mathrm{P}<0.05$. B, The proliferation of HL-60/pAd-NLS-RAR $\alpha$ infected cells increased significantly when compared with controls. Data was expressed as mean $\pm \mathrm{SD} . * \mathrm{P}<0.05$.

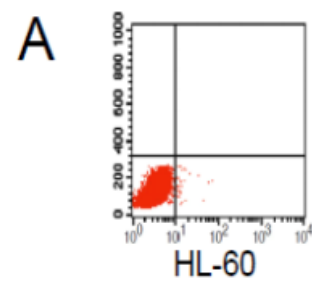

B

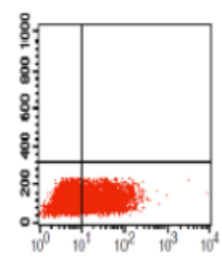

HL-60
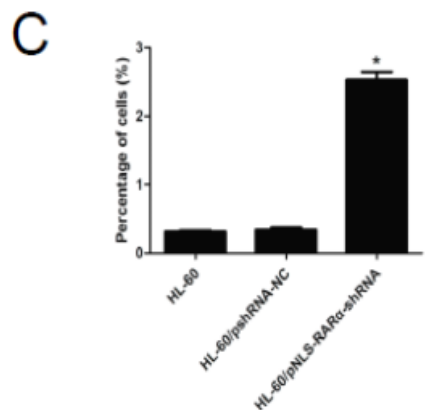

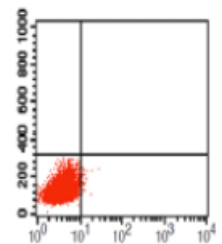

HL-60/pshRNA-NC

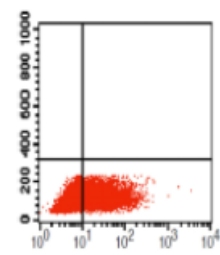

HL60/pAd-KZ

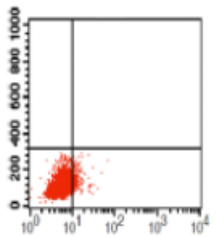

HL-60/pNLS-RAR a -shRNA

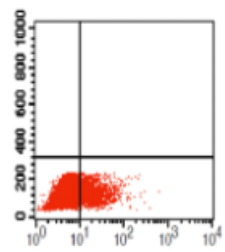

HL-60/pAd-NLS-RAR $a$

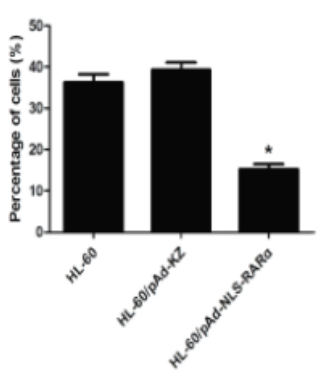

Figure 5. Differentiation rate in different cells. A and C, The differentiation rate of transfected HL-60 cells was detected by FCM. The differentiation rate of HL-60/pNLS-RARa-shRNA cells increased significantly ( $* \mathrm{P}<0.05)$. B and $\mathrm{D}$, The differentiation rate of infected $\mathrm{HL}-60$ cells treated with ATRA was detected by FCM. The differentiation rate of HL-60/pAd-NLS-RARa cells was reduced dramatically $(* P<0.05)$. 


\section{A}
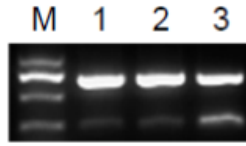

$\beta$-actin $700 \mathrm{bp}$

C-MYC 248bp
C

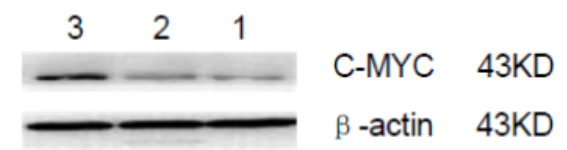

B

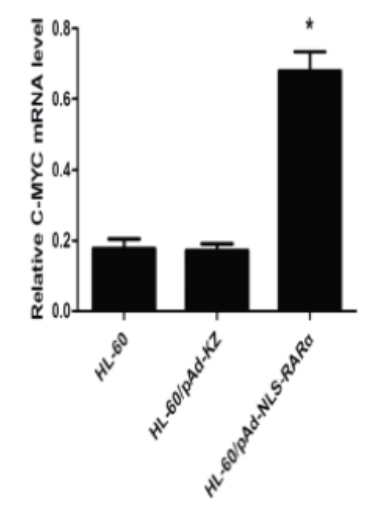

D

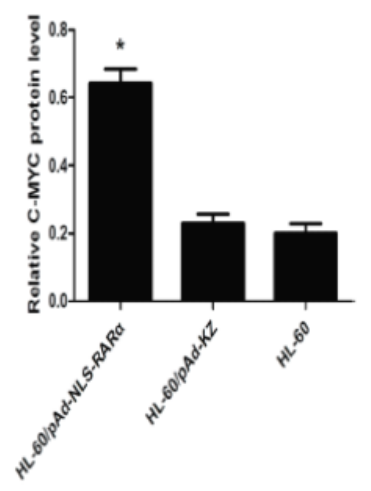

Figure 6. Expression of C-MYC gene in HL-60/ pAd-NLS-RARa cells. A and B, Detection of mRNA expression of C-MYC by RT-PCR. When compared with control groups, the expression of C-MYC in HL-60/pAD-NLS-RARa cells increased significantly $(P<0.05)$. C and D, Detection of protein expression of C-MYC gene by Western blot assay. The change in the protein expression of C-MYC gene was consistent with that in mRNA expression (lane I: HL-60 cells; lane 2: HL-60/pAd-KZ cells; lane 3: HL-60/pAd-NLS-RARa cells).

\section{Discussion}

The fusion gene PML-RARa is a marker of APL and plays an important role in the occurrence and development of this disease. Its importance has been confirmed in transgenic mice [20]. However, there is evidence that the entire PML-RARa fusion protein is not necessary for the development of APL [21, 22]. Studies have shown that in early myeloid cells, the PML-RARa protein can be cleaved by NE within the PML component, leaving the NLS domain fused to RARa, resulting in a new mutant of RARa, named NLS-RARa. We speculate that the NLS-RARa fusion functions differently to the wild-type RARa, and may play a vital role in APL. In addition, the effect of NLS-RARa on leukemia cells has not been completely elucidated.

Human wild-type RARa acts as a ligand-dependent transcription factor involved in multiple functions [23], including cellular proliferation and differentiation. Our present findings demonstrate that NLS-RARa promotes the proliferation of leukemic cells and interrupts the pro-differentiation signal of ATRA.

The NLS-RARa was silenced with shRNA. RNA interference is a gene silencing process mediated by double-stranded RNA, and an effective method for gene silencing.

Recombinant adenovirus technology represents a powerful method to genetically modify leukemia cells. Therefore the recombinant adenovirus
pAd-NLS-RARa was constructed and used to express the NLS-RARa gene, achieving high levels of stable expression in leukemia cell lines (HL-60 cells).

As shown in Figure 2 and Figure 3, the NLS-RARa was successfully silenced and over-expressed, respectively. The proliferation and differentiation of leukemic cells in vitro were investigated in cells with down-regulation or up-regulation of NLS-RARa expression. MTT assays showed that the proliferation of HL-60/pNLS-RARa-shRNA transfected cells was inhibited in a time-dependent manner, but that of HL-60/pAd-NLS-RARa infected cells was markedly promoted when compared with controls. These findings indicated that NLS-RARa could promote the proliferation of HL-60 cells. Furthermore, when compared with controls, the differentiation rate of the HL-60/pNLS-RARa-shRNA transfected group increased significantly. However, the differentiation rate of the HL-60/pAd-NLS-RARa infected group decreased significantly. These findings demonstrated that over-expression of NLS-RARa could promote the proliferation of APL cells and inhibit their differentiation induced by $2.5 \mu \mathrm{mol} / \mathrm{L}$ ATRA, in marked contrast to the biological effect of RARa. Thus, we confirmed that NLS-RARa played important role in the differentiation of HL-60 cell, and it is likely to be fairly important to the genesis and development of APL. The further study of NLS-RARa gene will be very necessary and valuable.

It has been noted that MYC was one of the most prevalent oncogenes in human cancer, and particu- 
larly in hematopoietic neoplasias [24, 25]. It is also involved in a number of fundamental functions of cell biology, such as control of proliferation a differentiation, energy production, cell size [26, 27, 28]. Moreover, the inhibition of myeloid cell differentiation was one of the first biological effects described for MYC [28]. It has been shown that PML-RARa induced MYC expression $[29,30]$. In this paper, C-MYC was detected by RT-PCR and Western blot assays, showing that over-expression of NLS-RARa could increase the C-MYC expression. This suggests that C-MYC is a downstream target of NLS-RARa gene.

In summary, wild-type RARa inhibits cell growth and promotes differentiation in response to ATRA, while NLS-RARa has the opposite effect. We speculated that this difference could be associated with abnormal cellular localization of the RARa domain, which is likely to result in abnormal protein-protein interactions. This would alter the original signal pathway and biological function, thus promoting the occurrence and development of APL.

\section{Acknowledgements}

This study was supported by the National Natural Science Foundation of China (No. 81171658) and Natural Science Foundation Project of CQ CSTC (No. 2011BA5037).

\section{Competing Interests}

The authors have declared that no competing interest exists.

\section{References}

1. Mattei MG, Petkovich M, Mattei JF, et al. Mapping of the human retinoic acid receptor to the Q21 band of chromosome 17.Hum. Genet. 1988; 80:186-188.

2. Evans RM. The steroid and thyroid hormone receptor superfamily. Science. 1988; 240:889-895

3. Escriva H, Bertrand S, Laudet V. The evolution of the nuclear receptor superfamily. Essays Biochem. 2004; 40:11-26. Review.

4. McEwan IJ. Nuclear receptors: one big family. Methods Mol Biol. 2009; 505:3-18.

5. Glass CK, DiRenzo J, Kurokawa R, Han ZH. Regulation of gene expression by retinoic acid receptors. DNA Cell Biol. 1991; 10:623-638. Review.

6. Rochette-Egly C, Germain P. Dynamic and combinatorial control of gene expression by nuclear retinoic acid receptors. Nucl Recepet Signal. 2009; 7:e05.

7. Gronemeyer H, Gustafsson JA, Laudet V. Principles for modulation of the nuclear receptor superfamily. Nat Rev Drug Discov. 2004; 3:950-964.

8. Aranda A, Pascual A. Nuclear hormone receptors and gene expression. Physiol Rev. 2001; 81: 1269-1304.

9. Saurin AJ, Borden KL, Boddy MN. et al. Does this have a familiar RING? Trends Biochem Sci. 1996; 21: 208-14.

10. Kakizuka A, Miller Jr WH, Umesono $\mathrm{K}$, et al Chromosomal translocation $\mathrm{t}(15 ; 17)$ in human acute promyelocytic leukemia fuses RAR alpha with a novel putative transcription factor, PML. Cell. 1991; 66:663 -674.

11. Soo JY, Seob EJ, Jae HL. A complex, four-way variant $\mathrm{t}(15 ; 17)$ in acute promyelocytic leukemia. Cancer Genetics and Cytogenetics. 2006; 167:168-71.

12. Pollock JL, Westervelt P, Walter MJ, et al. Mouse models of acute. Promyelocytic leukemia. Curr Opin Hematol. 2001; 8(4):206-211.

13. Laurenzana A, Pettersson F, Miller WH. Role of PML/RARa in the pathogenesis of APL. Drug Discovery Today: Disease Mechanisms. 2006; 3:499-505

14. Grisolano JL, Wesselschmidt RL, Pelicci PG, et al. Altered myeloid development and acute leukemia in transgenic mice expressing PML-RARa under control of cathepsin $\mathrm{G}$ regulatory sequences. Blood. 1997; 89:376-87.

15. He LZ, Tribioli C, Riv R, et al. Acute leukemia with promyelocytic features in PML/RARa transgenic mice. Proc Natl Acad Sci USA. 1997; 94:5302-7.
16. Westervelt P,Lane AA,Pollock JL,et al. High-penetrance mouse model of acute promyelocytic leukemia with very low levels of PML-RARa expression. Blood. 2003; 102:1857-65.

17. Early E,Moore MA, Kakizuka A, et al. Transgenic expression of PML/RARa impairs myelopoiesis. Proc Natl Acad Sci USA. 1996; 93:7900-4.

18. Lane AA, Ley TJ. Neutrophil elastase cleaves PML-RARa and is important for the development of acute promyelocytic leukemia in mice. Cell.2003; 115:305-18.

19. Takahashi N. Induction of cell differentiation and development of new anticancer drugs. Yakugaku Zasshi. 2002; 122:547-563.

20. Wartman LD, Welch LJ, Uy GL, et al. Expression and function of PML-RARA in the hemotopoietic progenitor cells of Ctsg-PML-RARA mice. PLoS One. 2012; 7: e46529.

21. Hayakawa F, Privalsky ML. Phosphorylation of PML by mitogen-activated protein kinases plays a key role in arsenic trioxide-mediated apoptosis. Cancer Cell. 2004; 5:389-401.

22. Shima $Y$, Shima T, et a1. PML activates transcription by protecting HIPK2 and p300 from SCFFbx3-mediated degradation. Mol Cell Biol. 2008; 28:7126-38.

23. Melnick A, Licht JD. Deconstructing a disease: RARa, its fusion partners, and their roles in the pathogenesis of acute promyelocytic leukemia. Blood. 1999; 93:3167-3215.

24. Nesbit CE, Tersak JM, Prochownik EV. MYC oncogenes and human neoplastic disease. Oncogene. 1999; 18:3004-3016.

25. Vita M, Henriksson M. The Myc oncoprotein as a therapeutic target for human cancer. Semin Cancer Biol. 2006; 16:318-330.

26. Oster SK, Ho CS, Soucie EL, Penn LZ. The myc oncogene: marvelouslY complex. Adv Cancer Res. 2002; 84:81-154.

27. Eilers M, Eisenman RN. Myc's broad reach. Genes Dev. 2008; 22·2755-2766.

28. Leon J, Ferrandiz N, Acosta JC, Delgado MD. Inhibition of cell differentiation: a critical mechanism for MYC-mediated carcinogenesis? Cell Cycle. 2009; 8:1148-1157.

29. Muller-Tidow C, Steffen B, Cauvet T, Tickenbrock L, Ji P, et al. Translocation products in acute myeloid leukemia activate the Wnt signaling pathway in hematopoietic cells. Mol Cell Biol. 2004; 24:2890-2904.

30. Rice KL, Hormaeche I, Doulatov S, et al. Comprehensive genomic screens identify a role for PLZF-RARalpha as a positive regulator of cell proliferation via direct regulation of c-MYC. Blood. 2009; 114:5499-5511. 